\title{
The study on the influence factors of locomotive energy consumption
}

\section{based on $\mathrm{AHP}^{*}$}

\author{
Gao Zhiyuan, Wang Lie \\ (The institute of transportation and economic of china academy of railway \\ sciences 100081 \\ BeiJing )
}

\section{Keywords: The locomotive Energy consumption Influencing factor}

Abstract: As the main backbone mode of transportation in China, railway transportation is of great significance for the study of energy consumption influencing factors. This paper analyses the background of railway goods transportation and energy consumption in our country, and on the basis of summarizing the research results at home and abroad, mainly from the mobile devices, operating environment, the organization plan and train control four aspects analyzes the influence factors of railway freight locomotive traction energy consumption, and USES AHP to the influence factors to give corresponding weights.

\section{Introduction}

Railway locomotive traction energy consumption accounts for the proportion of national railway energy consumption is very big, the traction energy consumption as an important part of railway operation cost, and railway construction, energy and environmental policies of the state, and so on has the close relation, large energy saving potential. In the context of energy conservation and emission reduction advocated by the government, it is of great concern to strengthen the conservation and management of traction energy resources of railway locomotives and improve the efficiency of energy resources utilization. However, the current energy consumption of locomotives is difficult to collect. As a result, the influencing factors to carry out the system of locomotive traction energy consumption study, the analysis of China's railway industry energy consumption structure and realize the goal of energy conservation and emissions reduction has the vital role, to reduce the transportation cost, improve the economic benefit, improving the capacity of scientific and technological progress, and promote sustainable development of the railway health is of great importance.

At present, many scholars have studied this. The influence factors of xue yanbing and wang $\operatorname{lie}^{1}$ on the traction energy consumption of the train have been comprehensively summarized. Yang jun and yu qian et al. ${ }^{2}$ analyzed the current situation of energy consumption of the railway without electricity meters in China, and pointed out the reasons for the large errors in the energy consumption statistics. Chen tao ${ }^{3}$ analyzed the composition of railway energy consumption and its influence factors, and studied three methods to measure the energy consumption of high-speed trains. Li-zhen huang ${ }^{4} \mathrm{On}$ the basis of summarizing the existing research results at home and abroad, mainly from the mobile devices, operating environment, the organization plan and train

\footnotetext{
* China railway corporation project: Optimization and verification of locomotive energy saving strategy based on big data analysis (project NO. : 2016j008-A)

Gao zhiyuan (1986 -), male, management Ph.D., assistant researcher of the institute of transportation and economic research of China railway research institute, research direction: railway transportation economy and locomotive energy consumption, Email: gaozhiyuan@ rails.cn.
} 
control four aspects analyzes the influence factors of railway freight locomotive traction energy consumption. Mr Chen ${ }^{5}$, Based on the energy consumption of Beijing rail transit operation lines data, analysis the main factors influencing the energy consumption of urban rail transit, and through multiple linear regression method, establish the traction energy consumption estimation model based on operational data.

\section{Selection of assessment method}

(1)Determine the importance of indicators

Using the $x_{i}(i=1,2 \ldots n)$ magnitude of the importance of the indicators, Remember $x_{i} \geq x_{j}$ that the importance of representation $x_{i}$ and $x_{j}$ is greater than or equal to both. Sort of the importance of $x_{i}$, Remember $x_{i}^{*}$ is the first index after sorting, So there are $x_{1}^{*}>x_{2}^{*} \ldots>x_{n}^{*}$, This is the formula for sorting $x_{i}$ by importance.

(2) The relative importance of two indexes is given

The magnitude of the magnitude of $x_{k-1}$ and $x_{k}$ is measured in $(k=2,3 \ldots n)$, The value of $x_{k-1}$ and $x_{k}$ is shown in table 1 of the assignment of $r_{k}$.

Table 1 comparison between indicators based on G1 method

\begin{tabular}{ccccccc}
\hline $\begin{array}{c}\text { Degree of } \\
\text { importance }\end{array}$ & $\begin{array}{c}\text { Equally } \\
\text { important }\end{array}$ & $\begin{array}{c}\text { weak } \\
\text { importance }\end{array}$ & $\begin{array}{c}\text { General } \\
\text { important }\end{array}$ & $\begin{array}{c}\text { Obviously } \\
\text { important }\end{array}$ & $\begin{array}{c}\text { Highly } \\
\text { important }\end{array}$ & $\begin{array}{c}\text { absolute } \\
\text { importance }\end{array}$ \\
\hline$r_{i}$ & 1.0 & 1.2 & 1.4 & 1.6 & 1.8 & 2.0 \\
\hline
\end{tabular}

(3) The calculation of weight coefficient

According to the literature [5], If the rational assignment that the expert gives $r_{k}$ satisfies $r_{k-1} * r_{k}>1$,then $w_{n}=\left[1+\sum_{k=2}^{n} \prod_{i=k}^{n} r_{k}\right], \quad w_{k-1}^{*}=w_{k}^{*} * r_{k}, \quad k=(n, n-1 \ldots 2) 。$

\section{Construction of energy impact factor index system of railway locomotive}

Railway locomotive energy consumption affects many factors, such as equipment, environment, management and personnel can be divided into four categories: mobile devices, operating environment, transportation organization and train control. Among them, mobile equipment mainly refers to locomotive vehicle attributes, including locomotive traction characteristics, basic resistance characteristics, braking characteristics, etc. The transport organization scheme mainly includes the speed characteristics, the temporary speed limit, the stop plan, the operation time and other factors. The operating environment is mainly the slope, curve, bridge and other line attributes, and natural environment, such as climate and altitude, are also important factors affecting locomotive energy consumption. The different control modes of the train conductor have important influence on the energy consumption of the train. Therefore, the influence factors of locomotive energy consumption are more complex, and the above factors are analyzed in detail to distinguish the importance degree, which is conducive to the specific management of locomotive energy consumption. 
Tab. 2 The evaluation indexes of locomotive energy consumption influence factors

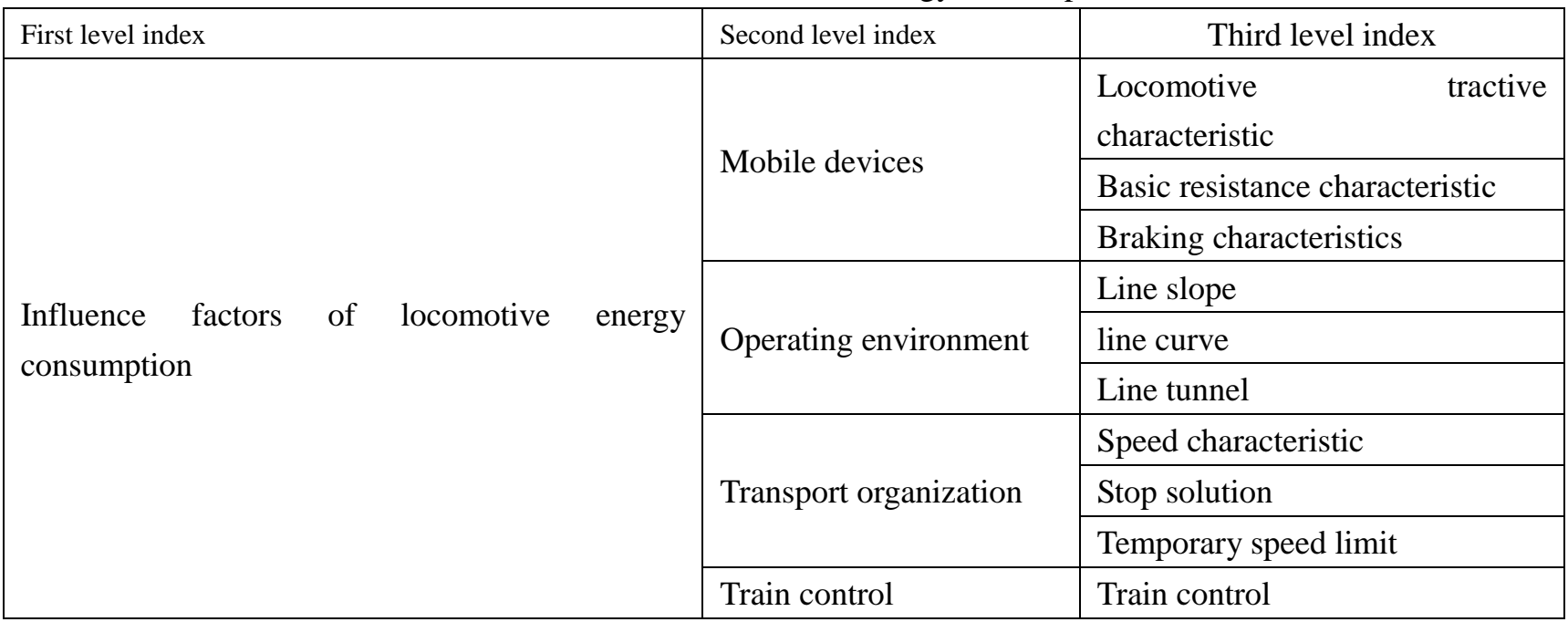

(1) Mobile devices

Railway transportation equipment is the infrastructure of railway transportation. At present, the transportation equipment and technical level of China's railway have made great progress compared with the past, and the main technical equipment has reached or close to the international advanced level.

(2) Operating environment

The operating environment refers to the external factors that directly influence the operation of the railway. The factors affecting the traction energy consumption of railway locomotives include the line attributes and the natural environment. The former belongs to the railway infrastructure, the latter mainly climatic conditions. The line attributes mainly include slope design (influence of slope, slope and slope size), curve radius (radius), tunnel setting, stop spacing and track smoothness.

(3) Transport organization

In the operation period after the completion of railway construction, different transportation organization schemes have a great influence on the traction energy consumption of the train in the case of the train property and operating environment are relatively fixed. The organization plan not only plays a key role in transportation service level, but also directly affects how much energy is consumed during transportation.

(4) Train control

Train manipulation refers to the driving behavior of the driver during the operation of the train, which is carried out by the human center. The different modes of operation have an important influence on the energy consumption of the train. , according to the related literature, locomotive vehicle characteristics and the condition of line speed, etc.

\section{The determination of the weight of influence factors of locomotive energy consumption}

According to the objective principle of evaluation, 10 experts in related industries were invited to rate the importance of each indicator, and according to the score, It is concluded that the importance of secondary index mobile devices $x_{1}$, operating environment $x_{2}$, transportation organization $x_{3}$ and train control $x_{4}$ is the degree of importance $x_{3}>x_{1}>x_{4}>x_{2}$, The sorted index size is $x_{1}^{*}>x_{2}^{*}>x_{3}^{*}>x_{4}^{*}$, The ratio of the importance of 
each indicator is respectively $r_{2}=\frac{w_{1}}{w_{2}}=1.4, r_{3}=\frac{w_{2}}{w_{3}}=1.2, \quad r_{4}=\frac{w_{3}}{w_{4}}=1.4$, So you can see that $r_{2} r_{3} r_{4}=2.352, \quad r_{3} r_{4}=1.68, r_{4}=1.4, \quad r_{2} r_{3} r_{4}+r_{3} r_{4}+r_{4}=5.432 。$

The formula is calculated according to the weight coefficient, $w_{4}^{*}=\left[1+\sum_{k=2}^{4} \prod_{i=2}^{4} r_{k}\right]^{-1}=0.1555$, $w_{3}^{*}=w_{4}^{*} *_{4}=0.2177, w_{2}^{*}=w_{3}^{*}{ }^{*} r_{3}=0.2612, w_{1}^{*}=w_{2}^{*}{ }^{*} r_{2}=0.3657$ 。

According to the formula for determining the weight of the weights above, the same can be obtained with the weight of the three-level index, as shown in table 3.

Tab.3 The evaluation index weight of locomotive energy consumption influence factors

\begin{tabular}{|c|c|c|c|c|c|}
\hline First level index & $\begin{array}{ll}\text { Second } & \text { level } \\
\text { index } & \\
\end{array}$ & weight & Third level index & weight & $\begin{array}{c}\text { The overall } \\
\text { weight }\end{array}$ \\
\hline \multirow{10}{*}{$\begin{array}{l}\text { Influence factors } \\
\text { of locomotive } \\
\text { energy } \\
\text { consumption }\end{array}$} & \multirow{3}{*}{ Mobile devices } & \multirow[t]{3}{*}{0.2612} & $\begin{array}{l}\text { Locomotive tractive } \\
\text { characteristic }\end{array}$ & 0.3656 & 0.0955 \\
\hline & & & $\begin{array}{l}\text { Basic resistance } \\
\text { characteristic }\end{array}$ & 0.3323 & 0.0868 \\
\hline & & & $\begin{array}{l}\text { Braking } \\
\text { characteristics }\end{array}$ & 0.3021 & 0.0789 \\
\hline & \multirow{3}{*}{$\begin{array}{l}\text { Operating } \\
\text { environment }\end{array}$} & \multirow[t]{3}{*}{0.2177} & Line slope & 0.3860 & 0.0840 \\
\hline & & & line curve & 0.3216 & 0.0700 \\
\hline & & & Line tunnel & 0.2924 & 0.0637 \\
\hline & \multirow{3}{*}{$\begin{array}{l}\text { Transport } \\
\text { organization }\end{array}$} & \multirow[t]{3}{*}{0.3657} & Speed characteristic & 0.6125 & 0.2240 \\
\hline & & & Stop solution & 0.2750 & 0.1006 \\
\hline & & & $\begin{array}{l}\text { Temporary speed } \\
\text { limit }\end{array}$ & 0.1125 & 0.0411 \\
\hline & Train control & 0.1555 & Train control & 0.2177 & 0.1555 \\
\hline
\end{tabular}

From the above calculation, it can be seen that, on the one hand, the weight of each index is different due to the different importance of energy consumption. In terms of indicators, the current velocity has the greatest influence on locomotive energy consumption, and the transport organization in the secondary index has the greatest impact on energy consumption, followed by mobile devices, operating environment and train control. On the other hand also can be seen that the locomotive traction energy consumption is influenced by many kinds of factor, mainly by the factors such as trains, line attribute and operation of, if can in certain lines of locomotive, vehicle, such as hardware environment and established running, train marshalling plan operations management situation, meet, on the basis of train operation safety, on time, by improving locomotive control method to realize the train running, is an economic and effective feasible energy saving way directly.

\section{Conclusion}

Mobile device, operating environment, organization plan and train control. The weight of each influencing factor is analyzed emphatically and the weight of locomotive energy consumption is quantified by AHP method.

(1) different factors have different impacts on locomotive energy consumption 
Speed has the greatest influence on locomotive energy consumption. The transport organization in the secondary index has the greatest impact on energy consumption, followed by mobile devices, operating environment and train control. The speed characteristic, stop plan and train control of the three-level index have great influence on locomotive energy consumption.

(2) optimize the economical and feasible path to reduce locomotive energy consumption

In a given traction locomotive, vehicle and line conditions such as hardware environment, and established the train running, train marshalling plan such as operation management situation, by improving the locomotive control method to realize the energy saving of the train operation, is an economic and effective feasible energy saving way directly.

\section{References}

1 XueYanbing,MaDawei,WangLie. Calculation Method of Energy Consumption in Train Traction[J].China Railway Sciene,2007(03):14-17.

2 YangJun, YuQian long. Design and Realization of Energy Management Information System for Intelligent Ammeter of Electric Locomotive[J].China Railway Sciene,2007(03):14-17. RAILWAY LOCOMOTIVE \&CAR,2005(05).

3 ChenTao. Comparative analysis of energy consumption and $\mathrm{CO} 2$ emissions of road transport and combined transport road/rail[D].2011.

${ }^{4}$ HuangLizhen. Analysis of influence factors on traction energy consumption of freight locomotive[D].2011.

${ }^{5}$ ChenFeng, Yangyang,LiuOuyang. Method of estimating traction energy consumption of urban rail transit[J]. Urban Rapid Rail Transit, 014,(02):90-93. 